\title{
Molecular Characterization of Cleidocranial Dysplasia (CCD) in the Western Region in KSA
}

\author{
Adel E. El-Tarras ${ }^{1,2 *}$, Mohammed A. El-Awady ${ }^{1,2}$, Samer, E. M. Ismail ${ }^{1}$, \\ Naglaa M. Kamal ${ }^{3,4}$ and Adnan A. Amin \\ ${ }^{1}$ Biotechnology and Genetic Engineering Unit, Scientific Research Deanship, \\ Taif University, KSA \\ ${ }^{2}$ Department of Genetics, Faculty of Agriculture, Cairo University, Cairo, Egypt \\ ${ }^{3}$ Department of Pediatric and Radiology, Al-Hada Armed forces Hospital, KSA \\ ${ }^{4}$ Department of Pediatrics, Faculty of Medicine, Cairo University, Cairo, Egypt \\ ${ }^{5}$ College of Medicine, Taif University, KSA \\ *Corresponding author
}

\begin{tabular}{|c|c|}
\hline & B S T R A C T \\
\hline $\begin{array}{l}\text { Cleidocranial } \\
\text { Dysplasia (CCD } \\
\text { Clavicular } \\
\text { hypoplasia, } \\
\text { RUNX2. }\end{array}$ & \multirow{4}{*}{$\begin{array}{l}\text { CCD is an autosomal dominant disorder caused by haploinsufficiency of Runt related } \\
\text { transcription factor (RUNX2) essential for osteoblast cell commitment and chondrocyte } \\
\text { maturation. A mutation of the RUNX2 (Core Binding Factor- } \alpha 1 \text { gene located at chromosome } \\
6 \text { p21) is usually caused CCD. In general, the estimated prevalence of CCD is under diagnosed } \\
\text { because of the relative lack of medical complications in comparison to other skeletal dysplasias. } \\
\text { No available data on the prevalence of CCD or its characterization in Saudi families. In the } \\
\text { present study, a Saudi family consists of a father, a mother, three daughters and one son was } \\
\text { analyzed for mutation detection in seven exons (2, } 4,5,6,7,8 \text { and } 9 \text { ) of RUNX2 gene with } \\
\text { flanking intronic boundaries. Diagnosis of CCD is mostly made on the basis of clinical and } \\
\text { radiographic features. The results of scans in the skull, jaw, chest, pelvis and hand and wrist } \\
\text { radiographs were evaluated. The clinical findings obtained clarified that the mother is normal, } \\
\text { but the father and the youngest daughter are affected with classical CCD, while the son and the } \\
\text { two elder daughters have dental anomalies only. While, we could not establish any phenotype- } \\
\text { genotype correlation, a heterozygous mutation was detected in Intron2; a (T) nucleotide is } \\
\text { substituted with a (C) nucleotide in the position } 5565 \text { of RUNX2 gene in the father, the son and } \\
\text { the three daughters. These findings suggest that it has a regulatory function related with teeth } \\
\text { differentiation. CCD clinical features are present at birth, but they are often diagnosed at a } \\
\text { much later time. Family history, pathognomonic clinical and radiographic findings play a } \\
\text { central role in the diagnosis of CCD. While this is the case, there is a necessity to develop an } \\
\text { early detection technique in order to enable early treatment of affected cases. }\end{array}$} \\
\hline Article Info & \\
\hline & \\
\hline & \\
\hline
\end{tabular}

\section{Introduction}

Delayed closure of the fontanels, hypoplastic or aplastic clavicles, midface hypoplasia, brachycephalic skull, moderately short stature and dental anomalies characterize Cleidocranial Dysplasia (CCD). Variable expression range from a mild isolated dental phenotype to severe CCD complicated by recurrent fractures and generalized osteoporosis. Abnormal dentition and clavicular hypoplasia are consistent features of this disorder (Mundlos, 1999; Quack et al., 1999; Otto et al., 2002). The term "severe 
CCD' has been used to describe patients who have CCD, osteoporosis and early recurrent fractures (Quack et al., 1999), and severe parietal bone hypoplasia (Cunningham et al., 2006). CCD (OMIM 119600) is an autosomal dominant disorder caused by haploinsufficiency of RUNX2 "Runt related transcription factor 2" (Mundlos, 1999). Mouse models and cell-culture studies reported Runx2 as a transcription factor, which has a crucial role in the regulation of osteoblast differentiation and the development and maintenance of mammalian bone and teeth (Li et al., 2011; Knezevic et al., 2011; Greenblatt et al., 2010).

The Runx2 gene is a master transcription factor of bone and plays a role in all stages of bone formation. The presence of RUNX2 in fully differentiated cells supports the concept that RUNX2 is also required in maintaining fully functional cells, at least in bone. The use of multiple promoters and alternative splicing of exons extends its diversity of actions. RUNX2 is also essential for the later stages of tooth formation, is intimately involved in the development of calcified tooth tissue, and exerts an influence on proliferation of the dental lamina. Furthermore, it regulates the alveolar remodeling process essential for tooth eruption and may play a role in the maintenance of the periodontal ligament (D'Souza et al., 1999; Quack et al., 1999; Ducy, 2000; Camilleri and McDonald, 2006; Cunningham et al., 2006). At the molecular level, Runx2 interacts with other proteins and regulatory complexes that either activate or repress transcription. Regulation of Runx2 occurs on multiple levels through multiple signaling pathways including BMPs, TGFb, FGF, and the canonical Wnt signaling pathway among others (Rodríguez et al., 2011; Ohyama et al., 2011).

Over 90 mutations of RUNX2 have been reported, including chromosomal translocations, deletions, insertions, nonsense and splice-site mutations, and missense mutation (Zheng et al., 2005), Cunningham et al., (2006), Lo Muzio et al., (2007), Lee et al., (2008) and Ryoo et al., (2010). All of these mutations result in loss of function, leading to only 1 functional copy of the gene and subsequent deficient bone formation in a syndrome known as cleidocranial dysplasia (CCD).

Although there is a wide spectrum in phenotypic variability ranging from isolated dental anomalies to the full-blown phenotype plus osteoporosis, several investigations failed to establish clear phenotype-genotype correlation (Zhou et al., 1999; Otto et al., 2002). Yoshida et al., (2002) described correlations between the mutational impairment of the Runt domain and the body height of CCD patients, and between the body height and number of supernumerary teeth. Lee et al., (2008) suggested in CCD patients whose mutation is not found by traditional sequencing, the deletion/duplication assay, RT-qPCR/MLPA, needs to be done particularly in a disease haploid insufficiency is thought to be the main cause. The deletion/duplication assay can improve the molecular diagnosis of CCD and likely change the statistics of molecular mechanism of this disease. Furthermore, Ott et al., (2010) screened 53 unrelated patients for copy number variations in the RUNX2 gene by quantitative PCR. Heterozygous deletions of different size were identified in 13 patients, and a duplication of the exons 1 to 4 of the RUNX2 gene in one patient. Thus, heterozygous deletions or duplications affecting the RUNX2 gene may be present in about $10 \%$ of all patients with a clinical diagnosis of CCD which corresponds to $26 \%$ of individuals with normal results on sequencing analysis. The authors therefore suggested that screening for intragenic deletions and duplications by qPCR or MLPA 
should be considered for patients with CCD phenotype in whom DNA sequencing does not reveal a causative RUNX2 mutation. Moreover, Ryoo et al., (2010) identified two CCD nuclear families and performed mutational analyses to clarify the underlying molecular genetic etiology. Mutational and phenotypic analyses showed that the severity of mutations on the skeletal system may not necessarily correlate with that of the disruption of tooth development. Therefore, characterization of RUNX2 mutations in CCD patients is important for RUNX2 functional studies.

\section{Materials and Methods}

\section{Patients}

A Saudi family from Taif governorate consists of 6 members, a father, a mother, one son and three daughters for the diagnostic features of CCD was examined clinically at Al-Hada Armed forces Hospital Taif City at the in the western region of KSA. The father (P1) and his third daughter (D3) have diagnosed to have classical CCD pattern. The other two daughters (D1, D2) and son (S1) were diagnosed to have dental anomalies only, while Mother is proved Normal. At the time of evaluation, peripheral blood samples from all the family members were collected into ethylene diaminetetra acetic acid (EDTA) tubes and stored at $-20^{\circ} \mathrm{C}$ until DNA extraction step. The study is carried out with the informed consent of the participating family.

\section{DNA amplification via PCR}

Genomic DNA was extracted from blood samples according to instructions of Blood DNA Preparation Kit (Thermo-Fisher; USA). Quality of extracted DNA was assessed via electrophoresis on agarose gel $1 \%$ and DNA concentration was estimated by UV Spectrophotometry. For mutation detection, exons 2 an 4 to 9 (NG_008020.1, GI:190341079) of the human RUNX2 gene were amplified using the primers indicated in Table 1 by polymerase chain reaction (PCR) from genomic DNA (gDNA) in a thermal cycler. The PCR amplification reactions were performed in Eppendorf ${ }^{\circledR}$ thermal cycler according to $\mathrm{Li}$ et al., (2009). The total reaction volume was set to $20 \mathrm{ul}$ of $2 \mathrm{X}$ superhot PCR Master Mix (Bioron; Germany) which contained 10 pmol of each of the specific primers shown in Table 1 (all directly synthesized by Macrogen Co., Seoul, South Korea). After the amplification, the PCR reaction products was electrophoresed with 100 bp DNA ladder (Fermentas, Germany) on

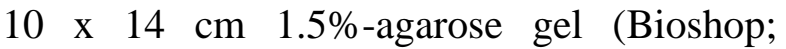
Canada) for 30 min using Tris-borate- EDTA Buffer. The gel was then stained with 0.5 $\mu \mathrm{gml}-1$ of ethidium bromide (Bioshop; Canada). Every resulting DNA fragment was confirmed by twice-repeated PCR of the gDNA products. All gels were visualized on a UV Transilluminator and documented using a GeneSnap 4.00- Gene Genius Bio Imaging System (Syngene; Frederick, Maryland, USA).

\section{DNA sequencing, sequence analysis and mutation detection}

The specific fragment for each of the seven RUNX2 exons via PCR was purified using purification kit (Jena Bioscience) according to the manufacturer's instructions and all specific fragments were directly sequenced using the same primers employed in the PCR amplification process on both forward and reverse directions. The results were repeated to ensure reproducibility. The products were sequenced using the Big Dye Terminator Cycle Sequencing Ready Reaction Kit (ABI Applied Biosystems, now Thermo-Fischer) on a 3130 Genetic Analyzer (Applied Biosystems, now Thermo-Fischer) and the Data collection software version 3.1 from ABI Applied Biosystems (now Thermo- 
Fischer) was used to collect the raw sequencing results. Every possible mutation was confirmed by twice-repeated sequencing. Additionally, all the purified DNA fragments were sent to Macrogen Co., Seoul, South Korea and were confirmed by twice-repeated sequencing using ABI 3730xl Genetic Analyzer (ABI). The cycle sequencing reactions were performed using the BigDye $\AA$ Terminator v3.1 Cycle Sequencing Kit (Applied Biosystems). Sequence analysis and base calling were carried out using Sequence Analysis Software version 3.1 from ABI Applied Biosystems (now Thermo-Fischer). After studying the sequence quality and consistency, the sequence alignment was carried out to the SLC26A3 gene on NCBI database. Following that, SeqScape software version 2.7 from ABI Applied Biosystems (now Thermo-Fischer) was employed for base-calling and mutation detection.

\section{Informative consent}

The study was approved by the research and ethical committees of Al-Hada Armed Forces Hospital and Taif University, Taif, Saudi Arabia. Written informed consents were obtained from the parents of the contributing family for the participation of the whole family in the current study.

\section{Results and Discussion}

In the current work, a Saudi family from Taif governorate consists of 6 members, a father, a mother, one son and three daughters was examined clinically for the diagnostic features of CCD. The father (P1) and his third daughter (D3) were diagnosed to have classical CCD pattern. The other two daughters (D1, D2) and son (S1) were diagnosed to have dental anomalies only, while Mother is proved Normal.

\section{Diagnosis}

A consanguineous family of 6 members with
5 affected was reported. The proband was the youngest daughter (D3, 5 month old) who presented clinically with failure to thrive and widely open fontanels and sutures. Her weight and height were between the $3^{\text {rd }} \& 5^{\text {th }}$ centile, while her head circumference was on the $90^{\text {th }}$ centile. She was found to have the classic clinical and radiologic findings of CCD. The clinical findings of cleido indicated Clavicular aplasia, resulting in narrow, sloping shoulders that can be opposed at the midline (Fig. 1-A).

Cranial showed abnormally large head, Midface hypoplasia, wide-open metopic suture results in separation of the frontal bones by a metopic groove, and broad flat forehead (Fig. 1- B, C). Additionally, the cranium is brachycephalic (Fig. 1-D). The Laboratory investigations showed normal serum calcium, phosphorus, alkaline phosphatase, parathyroid hormone and vitamin D levels. Thyroid function tests were within normal ranges. Radiographs of the youngest daughter (D3) revealed wide-open sutures, patent fontanels, delayed ossification of the skull and poor pneumatization of the paranasal, frontal, and mastoid sinuses; in addition to impacted, crowded teeth and supernumerary teeth (Fig. 2-A, B). Additionally, D3 radiographs showed absent clavicles and cone-shaped thorax with narrow upper thoracic diameter (Fig. 2-C). Also, radiographs revealed wide pubic symphysis, hypoplasia of the iliac wings, widening of the sacroiliac joints (Fig. 2-D).

The proband has an absent corpus callosum, a unique feature not previously reported in the literature (Fig. 3).

In general, intrafamilial clinical variability with mild to full-blown expression of the CCD phenotype was reported. Manifestations range from isolated dental anomalies to fully manifesting disease with poorly ossified cranium and absent clavicles. 
The father has the classic full blown picture of CCD. He is 37 year old, his fontanels are closed but he has large sized head, short stature and he failed to shed his deciduous teeth. The permanent teeth are impacted with supernumerary dentition as indicated by the (Fig. 4-A).

The father radiographs also revealed a hypoplastic clavicles and cone-shaped thorax with narrow upper thoracic diameter (Fig. 4B). The middle phalanges appear abnormally formed and short, particularly those of the second through fifth digits with hypoplastic distal phalanges (Fig. 4-C). The scanning additionally, revealed hypoplasia of the iliac wings, widening of the sacroiliac joints, large femoral neck (Fig. 5).

Concerning with the other family members, the elder 3 siblings ( 2 boys \& 1 girl) have only dental affection and the mother is clinically free.

\section{Mutation analysis}

Peripheral blood samples were obtained from all the family members. Genomic DNA was extracted from whole blood samples. The amplified fragments containing exons 2 and 4 to 9 and partially the flanking intronic regions of the human RUNX2 gene were visualized on agarose $1.5 \%$ to check the correct fragment size and purity). All the amplified fragments revealed the expected sizes according to table (1). The specific fragments then were directly sequenced in our lab in Taif University using the same primers employed in the PCR amplification process on both forward and reverse directions and it was repeated to ensure reproducible results. Additionally, all the purified DNA fragments were sent to Macrogen Co., Seoul, South Korea and were confirmed by twice-repeated sequencing. Following that, the SeqScape software version 2.7 from ABI Applied Biosystems (now Thermo-Fischer) was employed for base-calling and mutation detection. Only one heterozygous mutation where (T) changed too (C) on Intron 2 at position 5565 of RUNX2 gene was detected (Fig. 6). The mutation was detected in the father (P1) and his third daughter (D3). Also, the same mutation was detected in the other two daughters (D1 and D2) and the son (S1).

Cleidocranial dysplasia, a rare congenital disorder characterized by dysplasia, and even more rarely, by aplasia of the clavicles, largely goes unrecognized because patients with the condition seldom display functional limitation, pain, or other symptoms (Scott, 1988). The estimated prevalence of CCD is one per million, but it is most likely under diagnosed because of the relative lack of medical complications in comparison to other skeletal dysplasias (Cooper et al., 2001; Garg, et al., 2008 ).

In the current study, while the clinical and radiographic features were prominent and clearly indicated classical CCD, the mutation analysis studies for this family did not show any significant correlation with mutations in the seven studied exons and their intronic boundaries. In an agreement with our results, Mundlos et al., (1997), Zhou et al., (1999) and Otto et al., (2002) indicated that although there is a wide spectrum in phenotypic variability ranging from isolated dental anomalies to the full-blown phenotype plus osteoporosis, however, $40 \%$ of the cases of CCD appear spontaneously with no apparent genetic cause. In addition, no clear phenotype-genotype correlation has been established. Additionally, Tessa et al., (2003) failed to relate short stature to the altered Runt domain. Machuca-Tzili et al., (2002) studied two unrelated patients with classic CCD where DNA analysis revealed two novel mutations and three undescribed polymorphisms and no phenotype-genotype correlation could be established. 
Table.1 Primer pairs used to amplify seven exons of RUNX2 and respective annealing temperatures and products length

\begin{tabular}{cllcc}
\hline Exon & Forward primer $\left(5^{\prime} \rightarrow 3^{\prime}\right)$ & Reverse primer $\left(5 \rightarrow 3^{\prime}\right)$ & Tm ${ }^{\circ} \mathrm{C}$ & $\begin{array}{c}\text { Products } \\
(\mathrm{bp})\end{array}$ \\
\hline Exon 2 & GTTTGGGTATGGTTTGTATT & TTtTCTTCTGGTGAGGGTTA & 54 & 477 \\
Exon 4 & AACACTAAGTCCTGATAAGAC & GAAGGTGCTGATTTGTATACA & 54 & 354 \\
Exon 5 & TCATTGCCTCCTTAGAGATGC & GGACATGAAAGTGACACTAAC & 50 & 310 \\
Exon 6 & TATAAAGCAATTTGAAATGGAAGG & GTTTTGAAGTGAACACATCTCC & 57 & 428 \\
Exon 7 & TAAGGCTGCAATGGTTGCTAT & GTCACTGTGAGCATGGATGAG & 57 & 306 \\
Exon 8 & CTCTGGGAAATACTAATGAGGGAT & AGTGCCATGATGTGCATTTGTAAT & 55 & 351 \\
Exon 9 & TGTGGCTTGCTGTTCCTTTATG & GATACCACTGGGCCACTGCT & 58 & 631 \\
\hline
\end{tabular}

Figure.1 Youngest daughter (D3) showing (A) Clavicular aplasia, (B, C) Cranial dysplasia and (D) the cranium is brachycephalic
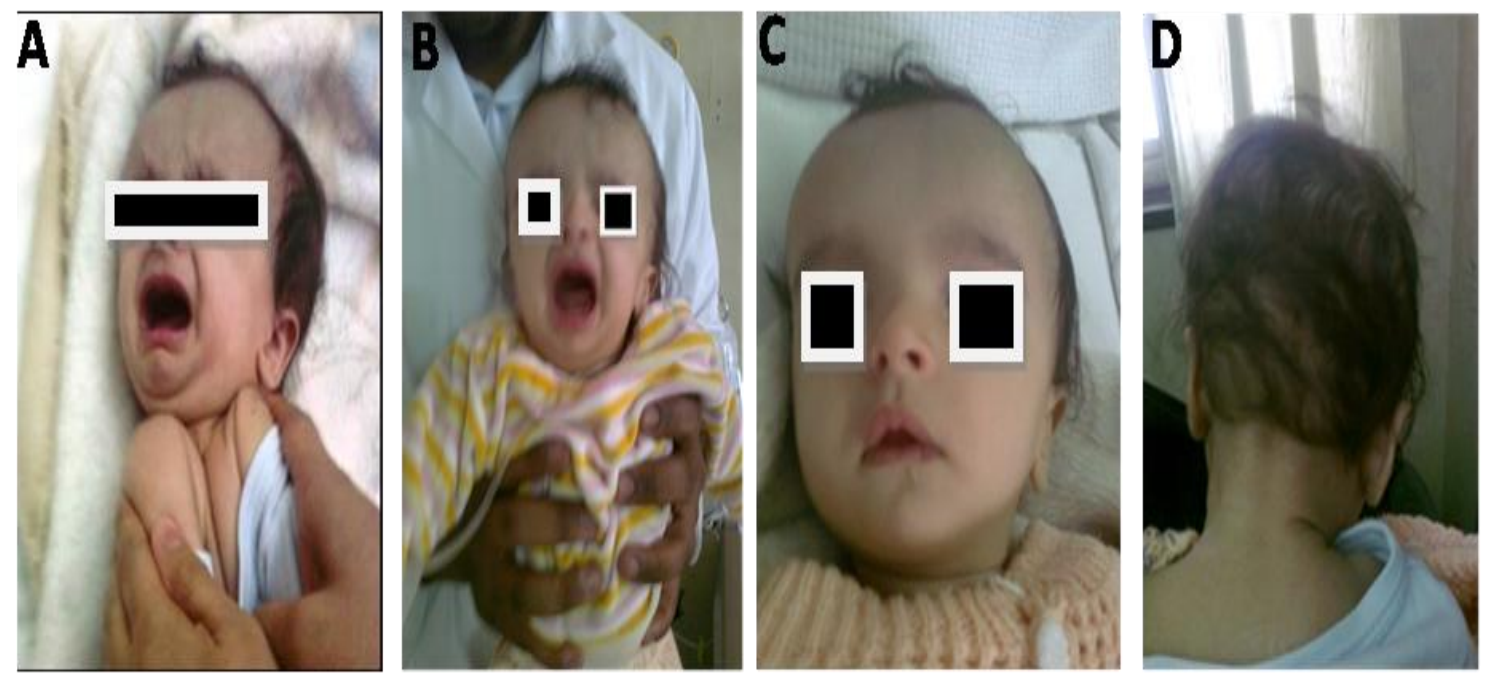
Figure.2 Youngest daughter (D3) radiographs showing cranial CCD features (A, B), clavicular CCD features (C) and wide pubic sympysis (D)
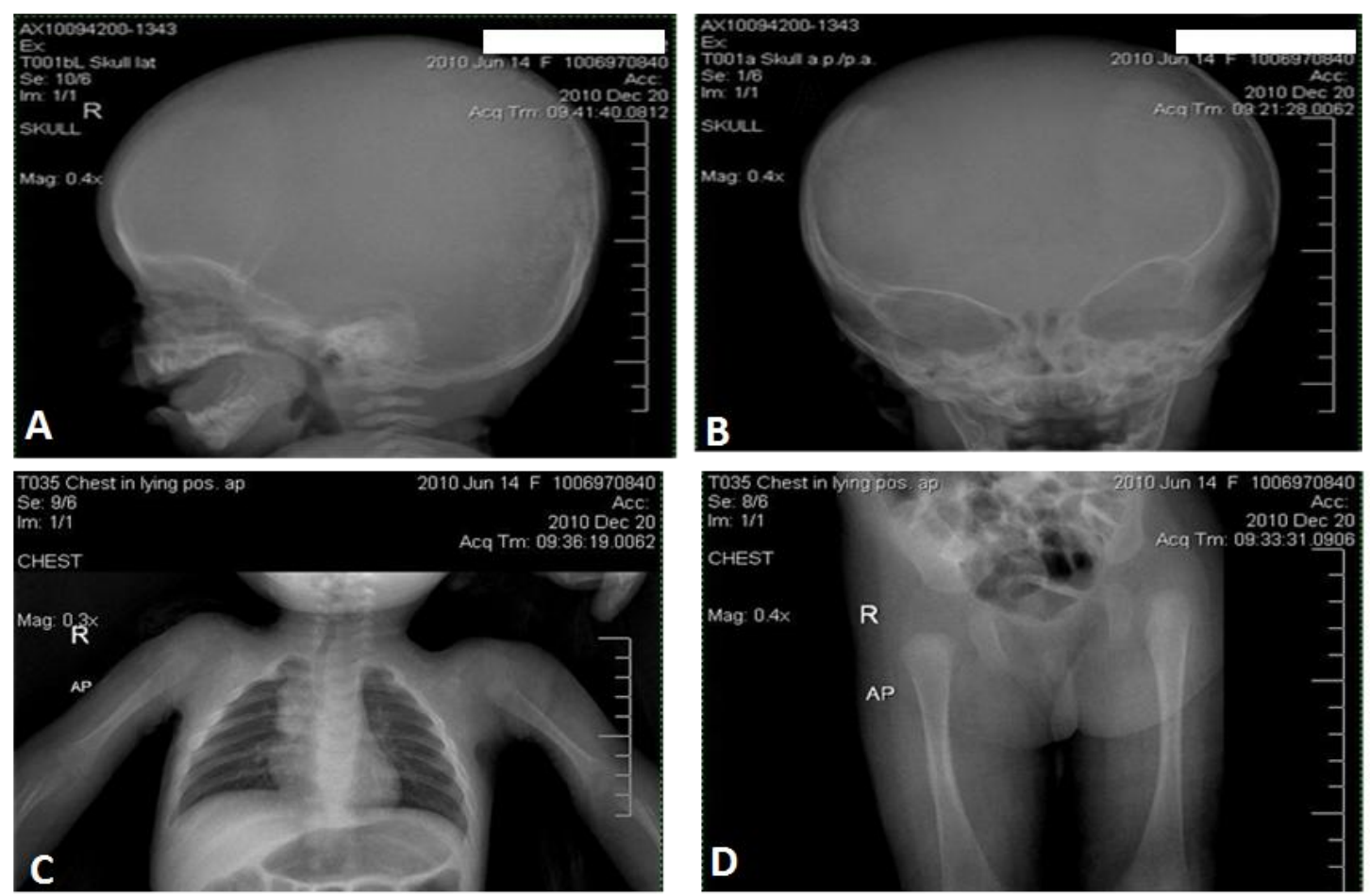

Figure.3 Youngest daughter (D3) radiographs showing corpus callosum
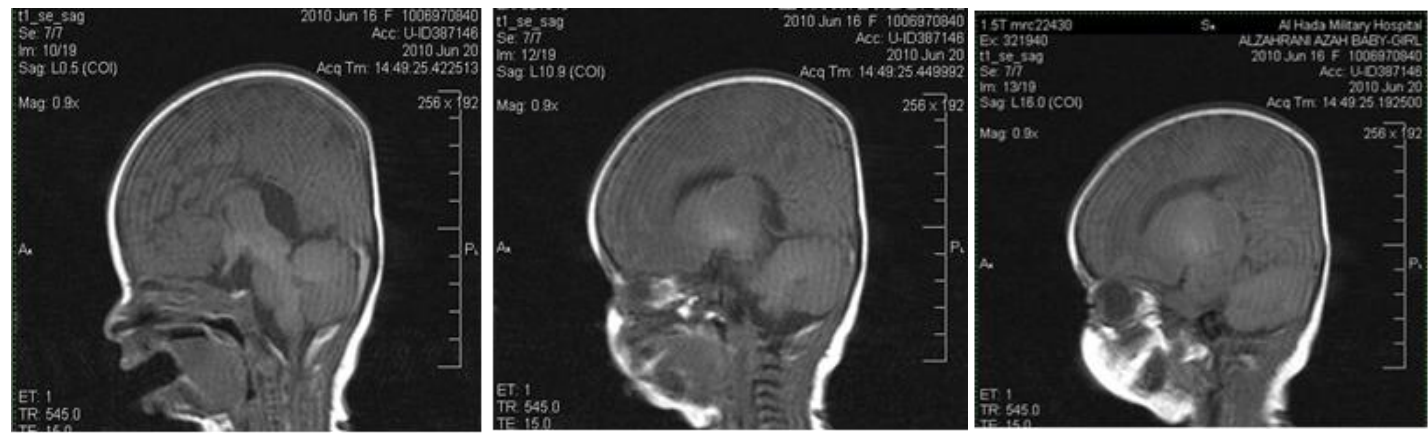

Figure.4 Father (P1) radiograph: (A) presence of wormian bones (small sutural bones), poor pneumatization of the paranasal, frontal, and mastoid sinuses. Impacted, crowded teeth and supernumerary teeth, (B) hypoplastic clavicles and (C) abnormal phalanges
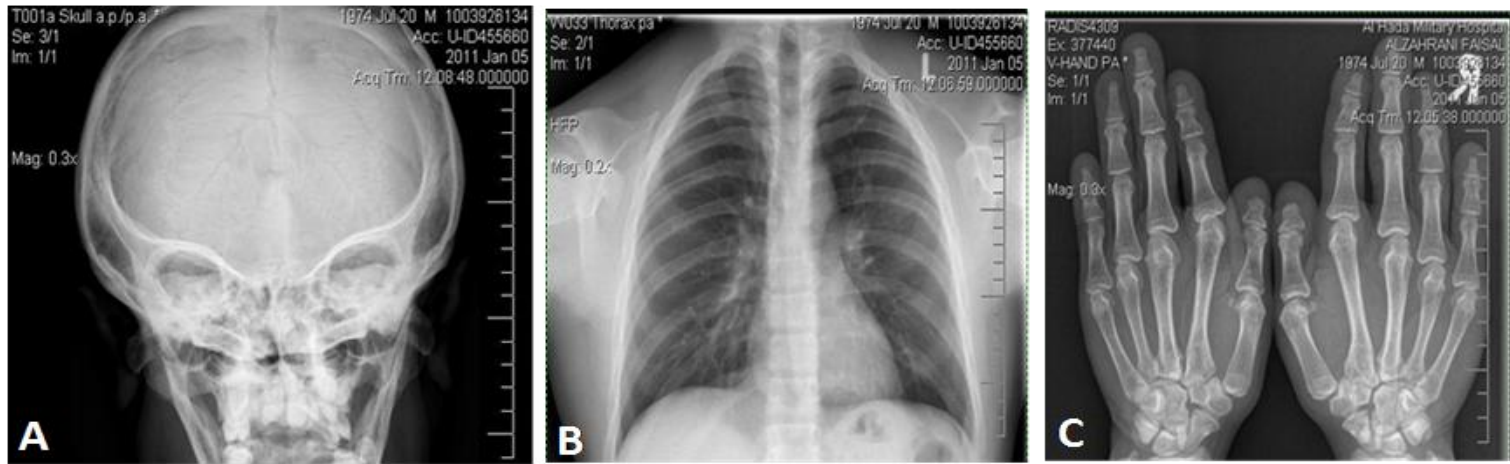
Figure.5 Father (P1) radiographs: hypoplasia of the iliac wings
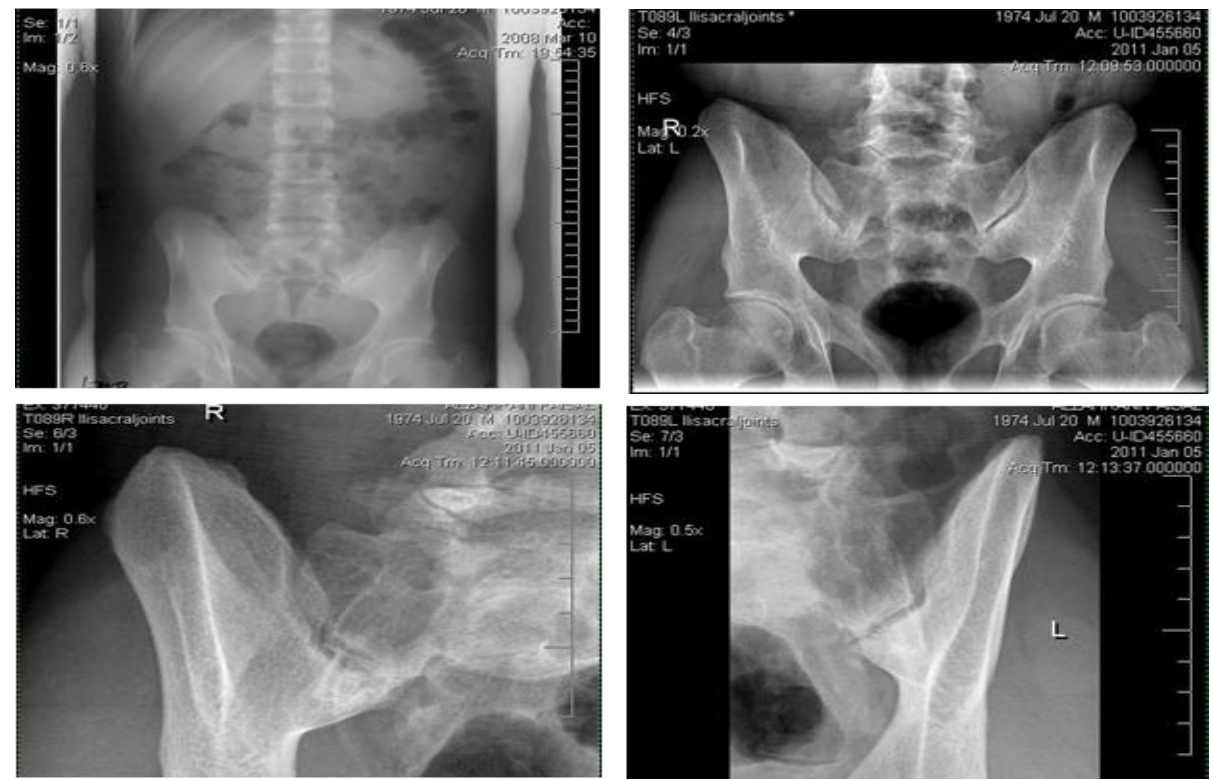

Figure.6 CCD Mutation (T to C) on Intron 2 at position 5565 of RUNX2 gene. S1: son, D1: daughter 1, D2: daughter 2, D3: daughter 3 and P1: Father

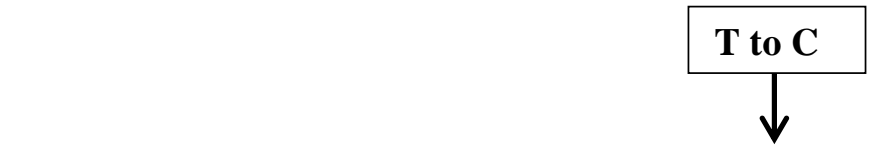

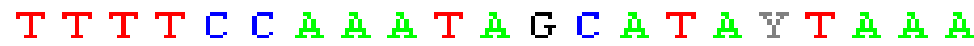
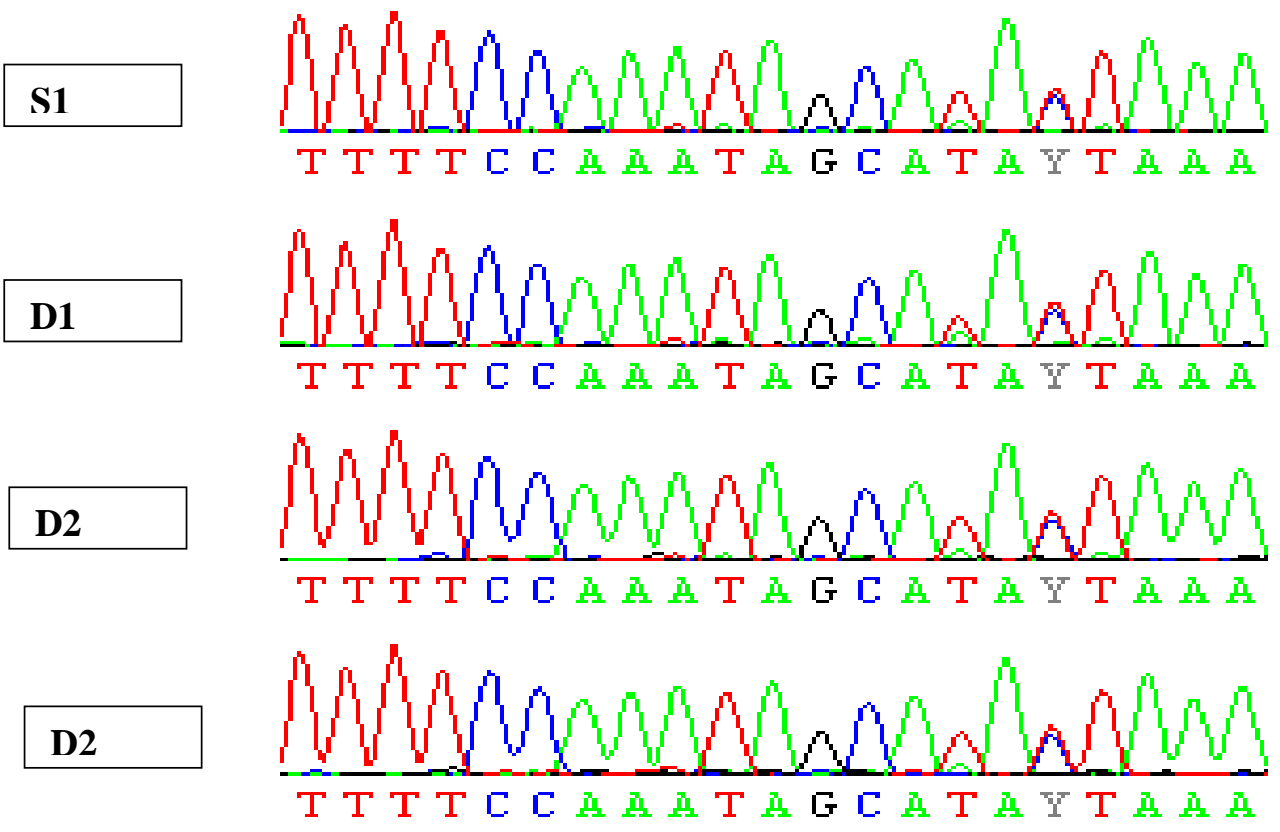

P1

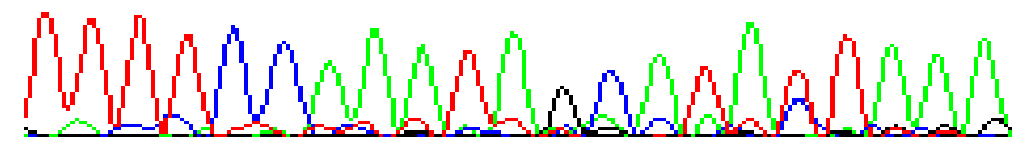


In contrast, Yoshida et al., (2002) described correlations between the mutational impairment of the Runt domain and the body height of CCD patients, and between the body height and number of supernumerary teeth. Additionally, Quack et al., (1999) demonstrated that mutations in the transcription factor CBFA1, on chromosome $6 \mathrm{p} 21$, are associated with CCD. There was no phenotypic difference between patients with deletions or frame shifts and those with other intragenic mutations, suggesting that $\mathrm{CCD}$ is generally caused by haploinsufficiency. However, they provided the first evidence that CBFA1 may help maintain adult bone, in addition to its function in bone development when one patient with severe CCD and a frame shift mutation in codon 402 had osteoporosis leading to recurrent bone fractures and scoliosis, Furthermore, in 2007, Lo Muzio et al., studied a 14-yr-old boy with typical CCD phenotype, the authors found a novel CBFA1/RUNX2 gene mutation. All of the amplified segments from the patient's CBFA1/RUNX2 gene were identical to those obtained in controls, except for the one spanning the exon 7 and intron/exon boundary regions. Direct sequencing of the PCR product showed a heterozygous T-to-A transition mutation at nucleotide 1182 in exon 7 , leading to Y394X mutation. The predicted protein product lacks 128 amino acids, including part of the PST domain. In addition, Xuan et al., (2008) suggested that an impaired runt domain contributes to the short stature of CCD patients. Wang et al., (2010) detected a single base-pair variant $\quad[\mathrm{c} .1259 \mathrm{C} \rightarrow \mathrm{T}$ (p.T420I)] in exon 7 in the CCD patients. This variant in the cDNA at position 1259 results in the substitution of threonine by isoleucine. It co-segregates with affected individuals of the family. There is no such sequence variant at that position in unaffected individual and one hundred unrelated normal controls, suggesting that the sequence aberration is pathogenic.
Nevertheless, we were able to detect only one heterozygous mutation where (T) changed to (C) on Intron 2 at position 5565 of RUNX2 gene (Fig. 6). It was detected in the father (P1), his third daughter (D3), the other two daughters (D1 and D2) and the son (S1). As this mutation in the intronic region of RUNX2 we could not confirm its effect. As CCD is autosomal dominant and because it is detected in the two cases with classical CCD (P1 and D3) and the other cases (S1, D1 and D2) with dental anomaly, we suggested that it has a regulatory function related with dental differentiation. Zhang et al., (2003) suggested that sequences flanking the Runt domain confer other biochemical activities such as transactivation. Additionally, Tessa et al., (2003) identified ten heterozygous base changes in the RUNX2 gene, including six novel mutations [c.522insA, c.389G $>$ A (W130X), c.662T $>\mathrm{G}(\mathrm{V} 221 \mathrm{G}), \quad \mathrm{IVS} 2+\mathrm{T}>\mathrm{A}$, c.1111_1129del19, and c.873_874delCA]. They did not establish a clear correlation between clinical features and genotype, the phenotypes of all patients analyzed falling within the range of variation described in CCD without an effect related to the length of the predicted protein. Furthermore, Ott et al., (2010) indicated that heterozygous deletions or duplications affecting the RUNX2 gene may be present in about $10 \%$ of all patients with a clinical diagnosis of CCD which corresponds to $26 \%$ of individuals with normal results on sequencing analysis. Accordingly, Lee et al., (2008) suggested that the deletion/duplication assay can improve the molecular diagnosis of CCD and likely change the statistics of molecular mechanism of this disease. Additionally, Ott et al., (2010) suggested that screening for intragenic deletions and duplications by qPCR or MLPA should be considered for patients with CCD phenotype in whom DNA sequencing does not reveal a causative RUNX2 mutation. 
To our knowledge this is the first study to try to establish the genetic background of CCD in Saudi Arabai. In fact, CCD is present in some Saudi families with interfamilial variations due to the consanguineous marriages. Although the clinical findings of CCD are present at birth, diagnosis of the disease is often delayed. CCD should be kept in mind by pediatricians as a cause of delayed closure of fontanelles. This highlights the importance of development an early detection techniques in addition to the physical examination in the diagnosis of this disease. Our results focus on the importance of studying further the main genetic controllers of $\mathrm{CCD}$ and the interrelation between them through different molecular techniques, including next generation targeted gene sequencing, association and functional genomics studies. By further studying the genotypic-phenotypic relation between the mutation detected and the symptoms expressed, an early detection technique that would facilitate the management of the affected individuals can establish. Also, it would enable to decrease the disorder burden by adding it to premarital screening program.

\section{References}

Baumert, U., Golan, I., Redlich, M., Aknin, J.J., Muessig, D. 2005. Cleidocranial dysplasia: molecular genetic analysis and phenotypic-based description of a Middle European patient group. Am. J. Med. Genet., 139A: 78-85.

Chang, D.J., Ji, C., Kim, K.K., Casinghino, S., McCarthy, T.L. and Centrella, M. 1998. Reduction in Transforming Growth Factor b Receptor I Expression and Transcription Factor CBFa1 on Bone Cells by Glucocorticoid. J. Biol. Chem., 273(9): 4892-4896.

Cooper, S.C., Flaitz, C.M., Johnston, D.A., Lee, B., Hecht, J.T. 2001. A natural history of cleidocranial dysplasia. Am. J. Med. Genet., 104(1): 1-6.

Cohen, M.M., Jr. 2001. RUNX Genes, Neoplasia, and Cleidocranial Dysplasia. American J. Med. Genetics, 104: 185-188.

Cooper, S.C., Flaitz, C.M., Johnston, D.A., Lee, B. and Hecht, J.T. 2001. A Natural History of Cleidocranial Dysplasia. American J. Med. Genetics, 104: 1-6.

D’Souza, R.N., Åberg, T., Gaikwad, J., Cavender, A., Owen, M., Karsenty, G. and Thesleff, I. 1999. Cbfa1 is required for epithelial-mesenchymal interactions regulating tooth development in mice. Develop., 126: 2911-2920.

Ducy, P., Zhang, R., Geoffroy, V., Ridall, A.L. and Karsenty, G. 1997. Osf2/Cbfa1: a transcriptional activator of osteoblast differentiation. Cell, 89: 747-754.

Ducy, P., Starbuck, M., Priemel, M., Shen, J., Pinero, G., Geoffroy, V., Amling, M., Karsenty, G. 1999. A Cbfa1dependent genetic pathway controls bone formation beyond embryonic development. Genes \& Develop., 13: 1025-1036.

Ducy, P. 2000. Cbfa1: A Molecular Switch in Osteoblast Biology. Developmental Dynamics, 219: 461-471.

Golan, I., Baumert, U., Wagener, H., Dauwerse, J., Preising, M., Lorenz, B., Niederdellmann, $H$. and Müßig, D. 2002. Atypical expression of cleidocranial dysplasia: clinical and molecular-genetic analysis. Orthod. Craniofacial Res., 5: 243-249.

Harada, H., Tagashira, S., Fujiwara, M., Ogawa, S., Katsumata, T., Yamaguchi, A., Komori, T. and Nakatsuka, M. 1999. Cbfa1 Isoforms Exert Functional Differences in 
Osteoblast Differentiation. The J. Biol. Chem., 274(11): 6972-6978.

Huang, L.F., Fukai, N., Selby, P.B., Olsen, B.R. and Mundlos, S. 1997. Mouse Clavicular Development: Analysis of Wild-Type and Cleidocranial Dysplasia Mutant Mice. Developmental Dynamics, 210: 33-40. Huang, G., Shigesada, K., Ito, K., Wee, H.J., Yokomizo, T. and Ito, Y. 2001. Dimerization with PEBP2 $\beta$ protects RUNX1/AML1 from ubiquitinproteasome-mediated degradation. The EMBO J., 20(4): 723-733.

Ito, Y. 1999. Molecular basis of tissuespecific gene expression mediated by the Runt domain transcription factor PEBP2/CBF. Genes to Cells, 4: 685696.

Kim, H.J., Nam, S.H., Kim, H.G., Park, H.S., Ryoo, H.M., Kim, S.Y., Cho, T.G., Kim, S.G., Bae, S.C., Kim, I.S., Stein, J.L., van Wijnen, A.J., Stein, G.S., Lian, J.B. and Choi, J.Y. 2006. Four Novel RUNX2 Mutations Including a Splice Donor Site Result in the Cleidocranial Dysplasia Phenotype. $J$. Cell. Physiol., 207: 114-122.

Knezevic, K,. Bee, T., Wilson, N.K., Janes, M.E., Kinston, S., Polderdijk, S., Kolb.Kokocinski, A., Ottersbach, K., Pencovich, N., Groner Y, de Bruijn M, Göttgens B, Pimanda, J.E. A Runx1.Smad6 rheostat controls Runx1 activity during embryonic hematopoiesis. Mol. Cell Biol., (14): 2817.26. Epub 2011 May 16.

Komori, T., Yagi, H., Nomura, S., Yamaguchi, A., Sasaki, K., Deguchi K, Shimizu, Y., Bronson, R.T., Gao, Y.H., Inada M, Sato M, Okamoto R, Kitamura Y, Yoshiki S and Kishimoto T. 1997. Targeted disruption of Cbfa1 results in a complete lack of bone formation owing to maturational arrest of osteoblasts. Cell, 89: 755.764.
Lee, K.S., Kim, H.J., Li Q.L, Chi X.Z, Ueta C., Komori, T, Wozney JM, Kim E.G, Choi, J.Y., Ryoo H.M and Bae S.C. 2000. Runx2 Is a Common Target of Transforming Growth Factor $\beta 1$ and Bone Morphogenetic Protein 2, and Cooperation between Runx2 and Smad5 Induces Osteoblast.Specific Gene Expression in the Pluripotent Mesenchymal Precursor Cell Line C2C12. Mol. Cell. Biol., 20(23): 8783-8792.

Lee, M.T., Tsai, A.C., Chou, C.H., Sun, F.M., et al. 2008. Intragenic microdeletion of RUNX2 is a novel mechanism for cleidocranial dysplasia. Genomic Med., 2: 45-49.

Li, J., Tsuji, K., Komori, T., Miyazono, K., Wranai, J.L., Ito, Y., Nifuji, A. and Noda, M. $\quad$ 1998. Smad2 Overexpression Enhances Smad4 Gene Expression and Suppresses CBFA1 Gene Expression in Osteoblastic Osteosarcoma ROS17/2.8 Cells and Primary Rat Calvaria Cells. The J. Biol. Chem., 273(47): 3100931015.

Li, Y., Pan, W., Xu, W., He, N., Chen, X., Liu H, Quarles, L.D., Zhou H and Xiao Z. 2009. RUNX2 mutations in Chinese patients with cleidocranial dysplasia. Mutagenesis, 24(5): 425-431.

Lo Muzio, L., Tete, S., Mastrangelo, F., Cazzolla, A.P., et al. 2007. A novel mutation of gene CBFA1/RUNX2 in cleidocranial dysplasia. Ann. Clin. Lab. Sci., 37: 115-120.

Machuca Tzili, L., Monroy Jaramillo, N., Gonzalez, del Angel, A,. Kofman, Alfaro, S. 2002. New mutations in the CBFA1 gene in two Mexican patients with cleidocranial dysplasia. Clin. Genet., 61(5): 349 -53.

Mundlos, S., Otto, F., Mundlos, C., et al. 1997. Mutations involving the transcription factor CBFA1 cause 
cleidocranial dysplasia. Cell, 89: 773779.

Mundlos, S. 1999. Cleidocranial dysplasia: clinical and molecular genetics. $J$. Med. Genet., 36: 177-182.

Ohyama, Y., Tanaka, T., Shimizu, T., Matsui H., Sato, H, Koitabashi N, Doi H, Iso T, Arai M, Kurabayashi M. Runx2/Smad3 Complex Negatively Regulates TGF. $\quad \beta$. Induced Connective Tissue Growth Factor gene Expression in Vascular Smooth Muscle Cells. J. Atheroscler. Thromb.

Ott, C.E., Leschik, G., Trotier, F., Brueton, L., Brunner, H.G., Brussel, W., Guillen, Navarro, E., Haase, C., Kohlhase, J., Kotzot, D., Lane, A., Lee, Kirsch, M.A., Morlot S, Simon M.E.H, Steichen, Gersdorf, E., Tegay D.H., Peters, H., Mundlos S and Klopocki E. 2010. Deletions of the RUNX2 Gene Are Present in about $10 \%$ of Individuals with Cleidocranial Dysplasia. Human Mutation: Mutation in Brief, 31: E1587.E1593.

Otto, F., Thornell, A.P,. Crompton, T., Denzel, A., Gilmour, K.C., Rosewell, I.R., Stamp, G.W., Beddington, R.S., Mundlos, S., Olsen, B.R., Selby, P.B. and Owen, M.J. 1997. Cbfa1, a candidate gene for cleidocranial dysplasia syndrome, is essential for osteoblast differentiation and bone development. Cell, 89: 765-771.

Otto, F., Kanegane, H., Mundlos, S. 2002. Mutations in the RUNX2 gene in patients with cleidocranial dysplasia. Hum. Mutat., 19: 209-16.

Quack, I., Vonderstrass, B., Stock, M., Aylsworth, A.S., Becker, A., Brueton, L., Lee, P.J., Majewski, F., Mulliken, J.B., Suri, M., Zenker, M., Mundlos S, Otto, F. 1999. Mutation analysis of core binding factor A1 in patients with cleidocranial dysplasia. Am. J. Hum. Genet., 65: 1268-78.
Rodríguez Carballo, E., Ulsamer, A., Susperregui, A.R., Manzanares Céspedes, C., Sánchez García, E., Bartrons R, Rosa, J.L, Ventura F. Conserved regulatory motifs in osteogenic gene promoters integrate cooperative effects of canonical Wnt and BMP pathways. J. Bone Miner. Res., 26(4): 718-29. doi $10.1002 / \mathrm{jbmr} .260$.

Ryoo, H.M., Kang, H.Y,. Lee, S.K., Lee, K.E. and Kim, J.W. 2010. RUNX2 mutations in cleidocranial dysplasia patients. Oral Dis., 16: 55-60.

Sakai, L.Y., Burgeson, R.E., Olsen, B.R., Rowe, D.W. and Gordon, S.L. 1996. Current Knowledge and Research Directions in Heritable Disorders of Connective Tissue. Matrix Biol., 15: 211-229.

Scott, R.D. 1988. Cleidocranial Dysplasia. An Enigma Among Anomalies. JOSPT, 10(5): 184-188.

Suda, N., Hamada, T., Hattori, M., Torii, C., Kosaki, K. and Moriyama, K. 2007. Diversity of supernumerary tooth formation in siblings with cleidocranial dysplasia having identical mutation in RUNX2: possible involvement of non genetic or epigenetic regulation. Orthod. Craniofacial Res., 10: 222-225.

Tang, S., Xu, Q., Xu, X., Du, J., Yang, X., Jiang, Y., Wang, X., Speck, N. and Huang, T. 2007. A novel RUNX2 missense mutation predicted to disrupt DNA binding causes cleidocranial dysplasia in a large Chinese family with hyperplastic nails. BMC Med. Genet., 8: 82.

Tessa, A., Salvi, S., Casali, C., Garavelli, L., Digilio, M.C., Dotti, M.T., Di Giandomenico, S., Valoppi, M., Grieco, G.S., Comanducci G, Bianchini G, Fortini D, Federico A, Giannotti A and Santorelli, F.M. 2003. 
Six novel mutations of the RUNX2 gene in Italian patients with cleidocranial dysplasia. Hum. Mutat., 22: 104.

Wang, G.X., Sun, R.P. and Song, F.L. 2010. A novel RUNX2 mutation (T420I) in Chinese patients with cleidocranial dysplasia. Genet. Mol. Res., 9(1): 4147.

Xuan, D., Li, S., Zhang, X., Hu, F., Lin, L., Wang, C. and Zhang, J. 2008. Mutations in the RUNX2 Gene in Chinese Patients with Cleidocranial Dysplasia. Annals of Clin. Lab. Sci., 38(1): 15-24.

Xuan, D.Y., Sun, X., Yan, Y.X., Xie, B.Y., Xu, P.P. and Zhang, J.C. 2010. Effect of Cleidocranial Dysplasia.Related Novel Mutation of RUNX2 on Characteristics of Dental Pulp Cells and Tooth Development. J. Cellular Biochem., 111: 1473-1481.

Yoshida, T., Kanegane, H., Osato, M., Yanagida, M., Miyawaki, T., Ito, Y., Shigesada, K. 2002. Functional analysis of RUNX2 mutations in
Japanese patients with cleidocranial dysplasia demonstrates novel genotype phenotype correlations. Am. J. Hum. Genet., 71: 724-738.

Zhang, L., Lukasik, S.M., Speck, N.A. and Bushweller, J.H. 2003. Structural and functional characterization of Runx1, CBF $\beta$, and CBF . SMMHC. Blood Cells, Mol. Dis., 30: 147-156.

Zheng, Q., Sebald, E., Zhou, G., Chen, Y., Wilcox, W., Lee, B. and Krakow, D. $2005 . \quad$ Dysregulation of Chondrogenesis in Human Cleidocranial Dysplasia. Am. J. Hum. Genet., 77: 305-312.

Zhou, G., Chen, Y., Zhou, L., Thirunavukkarasu, K., Hecht, J., Chitayat, D., Gelb, B.D., Pirinen, S., Berry, S.A., Greenberg, C.R., Karsenty, G. and Lee, B. 1999. CBFA1 mutation analysis and functional correlation with phenotypic variability in cleidocranial dysplasia. Hum. Mol. Genet., 8(12): 2311-2316.

\section{How to cite this article:}

Adel E. El-Tarras, Mohammed A. El-Awady, Samer, E. M. Ismail, Naglaa M. Kamal and Adnan A. Amin. 2017. Molecular Characterization of Cleidocranial Dysplasia (CCD) in the Western Region in KSA. Int.J.Curr.Microbiol.App.Sci. 6(4): 1373-1385. doi: https://doi.org/10.20546/ijcmas.2017.604.168 